\title{
Research on the Construction Process and Evaluation System of Low Carbon Audit of Petroleum Enterprises*
}

\author{
Zhihong Zhu, Dawei Xue, Baodi Liu \\ Northeast Petroleum University, Daqing, China
}

\begin{abstract}
With the low carbon audit emerge as the times require a low carbon economy, is an important guarantee for the healthy operation of economic society and all walks of life. As for the traditional auditing of derivative, the low carbon audit asides that the traditional auditing reviews the traditional financial statements and frequent business of enterprises, and begins to look to the more far-reaching low carbon projects auditing. However, from the present development situation of the low carbon audit, the biggest dilemma which the low carbon audit is facing is the lack of a perfect audit system. Based on the analysis of the connotation of low carbon audit, audit preparation, audit implementation, and audit end of three stages build the specific process of a low carbon audit of petroleum enterprise, then use expert opinion method, questionnaire survey method, and key performance indicators (KPI) to design a set of low carbon audit evaluation index system, which has the practical significance and the direction of important guidelines for low carbon audit for the smooth implementation of petroleum enterprise.
\end{abstract}

Keywords: low carbon audit, petroleum enterprise, evaluation system

China's economic development is at a peak, then the construction of industrial development and the construction of city have led to the consumption of energy larger and larger, and the waste is also becoming more and more serious. From the "Eleventh Five Year Plan" proposed controlling greenhouse gas emissions to the "Twelfth Five Year Plan" which will be energy-saving emission reduction of specific objectives included, low carbon economy has become an important part of sustainable development strategy in our country. For petroleum enterprises at home and abroad, in the face of "low carbon" trend, how to carry out the low carbon audit to evaluate the low carbon level should assume its social responsibility. This paper first defines the concept of low carbon audit, then the low carbon audit of petroleum enterprise process is carried on the thorough analysis, finally it constructs low carbon audit evaluation system of petroleum enterprises.

\footnotetext{
* The paper is supported by these fund projects: 2013 Youth Science Fund Project of Social Science of Northeast Petroleum University (2013QN201), Heilongjiang Province Philosophy Social Science Research Planning Project (13D007), Heilongjiang Province Philosophy Social Science Research Planning Project (12E144), 2014 Daqing Philosophy and Social Sciences Key Research Projects (DSGB 2014009), and 2013 Youth Science Fund Project of Social Science of Northeast Petroleum University (2013QN203).

Corresponding author: Zhihong Zhu, MA in management, associate professor, CPA of China, Petroleum Institute of Economics and Management, Northeast Petroleum University, Daqing, China; research field: theory and practice of auditing. E-mail: zzh79@126.com.

Dawei Xue, MA in management, Heilongjiang Bayi Agricultural University, China, associate professor, Petroleum Institute of Economics and Management, Northeast Petroleum University, Daqing, China; research field: theory and practice of auditing. E-mail: dqxuedawei@126.com.

Baodi Liu, MA candidate in accounting, Petroleum Institute of Economics and Management, Northeast Petroleum University, Daqing, China; research field: theory and practice of auditing. E-mail: baodiwogogo@163.com.
} 


\section{Connotation of Low Carbon Audit}

Low carbon audit is proposed by the relevant auditing organization, according to the national policies, laws and regulations, system, and standard, follow the auditing standards, the audited units or departments of the level of energy management, energy using equipment and production process status of energy utilization, energy, logistics, financial condition to conduct a comprehensive audit, is a special management behavior. Low carbon audit methods of economic benefit audit of reference, on-the-spot investigation, investigation, analysis, and inspection of enterprises economic or technical product are low carbon and carbon emissions, real, legitimate and effectiveness of the proposed review and low carbon audit report and decision. Low carbon audit aims to improve the audited units or departments of low carbon production management level, performance, and responsibility consciousness, and to put forward the improvement proposal. For low carbon audit has just started, the audit body should be based on the third party audit oriented, independently audit the use of social auditing independence and fairness of the implementation, the audited units of low carbon policy of low carbon technology promotion and related use of funds, and the use of the authority of the government audit to strengthen the entity under audit supervision and supervision, to ensure the effective implementation of the low carbon audit.

\section{Low Carbon Audit Process of Petroleum Enterprises}

To ensure the quality of audit work, is an important foundation to improve the audit work of value-added benefits, and to play the functions of the audit, and normative audit process is one of important factors of audit quality level. The traditional audit process is divided into: audit preparation, audit implementation, and auditing end of three stages. Low carbon audit, as an extension of traditional audit, the audit process should be improved in the traditional audit procedure.

\section{Preparation Stage of the Audit}

The traditional third party audit is to investigate and understand the basic conditions of the audited entity in the preparation stage of the main work, with the basic objective and content determination of the audit, and the audit unit signs a formal audit engagement letter. In the low carbon audit, these processes are still important, especially in the understanding of the basic conditions of the audited entity in the link, not only need to understand the background whether is related to audit units, such as the oil enterprise's scope of business, internal control system, industry development stage, and so on, but also the need for low carbon audit scope of petroleum enterprise to determine the specific to the more low carbon audit target of petroleum enterprises to determine the reasonable. Because the petroleum enterprises are in the production and business operation and the daily management activity, any one link in the chain is involved in energy consumption and greenhouse gas emissions, but emissions and emissions of different ways, the measurement methods, and the effects on the oil companies are not the same.

\section{The Implementation of the Audit}

The implementation stage of the audit is the audit work to carry out specific link, in the traditional audit in general, the implementation stage of the audit is mainly divided into compliance testing and substantive tests of two links, it is based on the enterprise internal whether to carry out the relevant rules and regulations for testing, to the enterprise production and management activities of the substantive investigation and evidence collection in depth, lay the foundation for the final audit report issued. Low carbon audit work, its focus should be on 
petroleum enterprises, lying in the greenhouse gas consumption, energy consumption and export or purchase, inventory and other relevant data for investigation of the objective monitoring and collection, and the use of reasonable way the data sorted and calculation analysis.

\section{The End Stage of the Audit}

End stage audit refers to the end of the implementation phase of audit, audit personnel prepare audit report according to the audit work papers, and submit relevant documents to organize the process of archiving. The low carbon audit, as the traditional audit of the new extension, should be considered as a new concept and idea, its implementation step by step to the oil production and operation of enterprises, therefore, in addition to the audit report and traditional auditing enterprises issued by the low carbon audit, low carbon audit should also be issued by the corresponding audited units of low carbon emission reduction advice and audit personnel should contact with the audited units and keep follow-up visits regularly to ensure the effect of low carbon audit. In the low carbon audit process of petroleum enterprises, while enterprise carbon emissions information, need not be disclosed with no specific provisions on the mandatory, however, some relative important elements such as carbon emissions data, energy sources, fate and related uses, energy efficiency are very important information. Therefore, in the report stage of low carbon audit, the audit personnel should calculate and explain the evaluation of carbon emissions, energy consumption of petroleum enterprise concrete and other aspects, according to the corresponding format list.

\section{Building Low Carbon Audit Evaluation System of Petroleum Enterprises}

At present, there is the overall angle on the low carbon economy evaluation system mainly based on the social and economic development, the system evaluates many aspects, such as regional low carbon policy, low carbon industry, etc. The low carbon audit on the concept of enterprise is more focused on low carbon production and management or supervision of enterprises emissions responsibility. From the range relative to the low carbon economy and low carbon evaluation, is more targeted. Therefore, this paper based on the research on the low carbon economy and low carbon society existing evaluation, constructs a low carbon audit evaluation system of petroleum enterprise by using key performance indicators.

\section{Design Ideas}

The key content of low carbon audit petroleum enterprises should be monitoring petroleum enterprise carbon energy displacement, however, it also covers the application of low carbon technologies and low carbon policy aspects, therefore, the internal relations of low carbon audit are complex and diversified. In the construction process of the index system, the audit personnel should try to choose the typical index which coverage is large and has more representativeness.

First of all, in the index system architecture, this paper will use three layer construction of index system to follow many scholars tend to architecture at present, through the three levels - the overall objective layer, criterion layer, and specific index layer it builds a low carbon audit evaluation index system. Secondly, in the index content, low carbon audit of petroleum enterprise mainly includes two levels - the overall goal which is to "low carbon enterprise" as the main strategic direction and a support of "low carbon production technology, low carbon management functions, low carbon economic benefits, and related policy support". The two systems complement each other, depend on each other. "Low carbon enterprise" is the overall audit objective of low carbon audit of petroleum enterprises, and the aspects such as "production techniques, the functions of 
management, economic benefits, and policy support" are the specific goals of petroleum enterprises to practice and maintain low carbon audit, they are also the main aspects to carry out specific audit work. Finally, this paper uses the method of key performance indicators (KPI) for final confirmation of index selection.

\section{Select the KPI}

KPI is a kind of method which is popular in enterprise performance management, it will be the enterprises' strategic objectives of decomposition layers upon layers, will be involved in the relationship of the enterprise performance system from complex to simple, then it will use representative indicators to analyze and evaluate for the all levels of the performance. This paper will adopt the method of KPI, to use the "overall goal of low carbon enterprise" by hierarchical decomposition; the basic ideas are as follows:

(1) Determining the index key areas according to the "low carbon enterprise" and "the specific connotation of low carbon audit". According to the main object of study and the main connotation of low carbon audit, it determines the guiding of "monitor carbon emissions of enterprise objectively, encourage enterprises to establish a low carbon transition, establish the development direction of low carbon of enterprise", and selects four key indexes of the field of "low carbon production technology, low carbon management functions, low carbon economic benefits, relevant policy support". And the low carbon production technology and its economic benefits are the core parts of the low carbon audit evaluation system;

(2) Using the method of questionnaire, selecting and determining the key evaluation index in the four fields of "low carbon production technology, low carbon management functions, low carbon economic benefits, and related policy support", so as to determine the final target system. In the process of determining the specific individual indicators, first of all, using the method of frequency statistics, to neaten the evaluation system of low carbon economy, the index of measurement and calculation on carbon emissions and the aspects of evaluation index, and then choose to use the frequency of the relatively high index, and use the specific connotation of low carbon audit to collect and screen all kinds of index, then select the index which has strong pertinence and systematic (KPI);

(3) Again, using the method of questionnaire, continue it to consult opinions with experts, analyze the membership of the relevant indicators, so as to select the more persuasive index. In the analysis of membership degree, the paper will consider low carbon audit of petroleum enterprises as a fuzzy set, see each evaluation index as an element, and analyze the membership of each index separately. Using the formula:

$$
\mathrm{RK}=\mathrm{MK} / \text { total number of valid samples }
$$

MK represents the total number of the expert selection, the most important times of the expert choosing. If $\mathrm{RK} \geq 0.3$, the membership test of the indicators is passed;

(4) Through correlation analysis, excluding the indexes which can explain each other, ensures the independence of indicators and further simplifies the index system. First of all, dimensionless processing for all indicators reduces the interference of different unit of evaluation indexes; secondly, the correlation test is carried out on the correlation between the indicators; finally, it eliminates the indexes that have high correlation.

\section{Low Carbon Audit Evaluation System of Petroleum Enterprises}

The first level of overall index. The first level of overall indicators of low carbon audit is the strategic goal of low carbon audit which is located, it is a strategic orientation of low carbon audit work, prompting oil enterprises to earnestly implement low carbon, to reduce energy-saving emission reduction, so as 
to achieve low carbon target of the management of petroleum enterprises and help the oil companies find out the energy effectively and weak points existing in the utilization of waste in the production process, to further tap the potential of energy saving of petroleum enterprises and the direction of the enterprise, thus reducing the petroleum enterprise energy consumption and production cost, improve the energy utilization efficiency.

\section{The second level of classification index}

(1) Low carbon production technology: Low carbon production technique is the most important part of the evaluation index system of low carbon audit in petroleum enterprises, which includes the measurement and calculation of carbon emissions of petroleum enterprises in the introduction of the development of low carbon technology and enterprise in the production process of each range. First, in the introduction of low carbon technology, the technology mainly includes the introduction, development, and utilization of new energy utilization, circular economy development, carbon capture technology, storage technology in the enterprise. Secondly, the more important is the calculation of petroleum enterprise in the production process of carbon emissions, such as other indirect emissions for which petroleum enterprises' upstream and downstream activities generated and carbon emissions related to outsourcing/contract manufacturing and lease;

(2) Low carbon economy benefit: Low carbon economy benefit mainly includes two aspects: The first one is the enterprise uses low carbon production technology to bring extra income. Due to the low carbon concept increasingly accepted by people, the future development prospects of low carbon industry is a piece of bright, low carbon technology can expand the sales of enterprise products to some extent and enhance the product price in the enterprise, then using the enterprise adopting low carbon technology to calculate the benefits of using low carbon technology for the increase of the benefits of the enterprise reliable to increase the reliability and persuasion of low carbon technology gains more intuitively and reliably;

(3) The management of functions on low carbon: With the deepening of low carbon concept, the core competitiveness of petroleum enterprises will gradually contain elements of low carbon development, the efforts on petroleum enterprises in the energy-saving emission reduction, will also become the important characteristics of consumers whom pay more attention to, the utilization of resource economically and efficiently, a full range of good low carbon management of enterprises, will be the only way that must be passed to future development of most business enterprises. Low carbon transition of petroleum enterprises, should also be gradually from the text on the original pure carbon emissions of enterprise to the internal management on the low carbon of enterprise, including purchasing management, human resources management, marketing management of low carbon, etc. Therefore, in the construction of low carbon audit evaluation system, the indexes related to management functions on low carbon should also be included, to monitor the real energy construction and emission reduction of enterprises roundly and high efficiency and low carbon;

(4) Relevant policy support: The implementation of low carbon technology, the publicity of low carbon awareness and other issues need to rely on the support and guide of policy adjusting. Improving the policy support system, can provide a wide range of financial support, tax incentives, and the right development orientation of the petroleum enterprises on practicing low carbon. And the implementation of the policy is an important performance of enterprises continuing to gain support in the way of low carbon, therefore, in the audit index related to policy support, should not only consider the external policy support on the audit work location, but also pay more attention to the sustainability and credibility of the implementation of low carbon policy in the enterprises. 
The third level of refinement indicators. Index selection: According to the design of the index system, this paper mainly adopts the method of expert opinion and literature review method to summarize and conclude the literatures which were published in recent years about low carbon economy evaluation index system, carbon audit index system, and determination on carbon emissions; in the first round of index screening, a total of four selected categories, nearly 60 indexes, form the preliminary "the screening questionnaire of petroleum enterprises in low carbon audit evaluation index system", and the questionnaire was passed through the way, such as transfer paper sample distribution and e-mail to relevant experts, they distinguish the degree of importance of specific indicators, the main way of discrimination taking on analysis methods related to membership degree to the method of general expert opinion. After the first initial round screening, nearly more than 10 non-correlation are eliminated and the correlation of the remaining 40 indicators are judging the remaining, its main purpose is to try to keep the index relatively independent and make index cover the max significance, finally obtain four classes and 20 items indexes in petroleum enterprises in the evaluation index system of low carbon audit, as shown in Table 1.

Table 1

The Evaluation Index System of Low Carbon Audit in Petroleum Enterprises

\begin{tabular}{|c|c|c|c|}
\hline & Classification index & Specific indicators & \\
\hline & & & $\begin{array}{l}\text { Low carbon technology research and development } \\
\text { funds accounted for the main business income }\end{array}$ \\
\hline & & Low carbon technology & $\begin{array}{l}\text { Low carbon transformation rate of traditional } \\
\text { industries }\end{array}$ \\
\hline & $\begin{array}{l}\text { Low carbon } \\
\text { production technology }\end{array}$ & & $\begin{array}{l}\text { The growth of greenhouse gas emissions in the } \\
\text { production realm }\end{array}$ \\
\hline & & $\begin{array}{l}\text { Corporate carbon } \\
\text { emissions monitoring }\end{array}$ & $\begin{array}{l}\text { The growth of greenhouse gas in the displacement } \\
\text { management sections }\end{array}$ \\
\hline & & & Rate of new energy saving building \\
\hline & & Low carbon industry & $\begin{array}{l}\text { The decrease rate of unit GDP (gross domestic } \\
\text { product) energy consumption }\end{array}$ \\
\hline The overall goals: & & benefit & Rate of return on net assets \\
\hline monitoring of & Low carbon economy & & The growth of output in the low carbon industrial \\
\hline $\begin{array}{l}\text { emissions objectively, } \\
\text { promote low carbon }\end{array}$ & benefit & Environment conctruction & $\begin{array}{l}\text { The comprehensive utilization rate of industrial } \\
\text { "three wastes" }\end{array}$ \\
\hline $\begin{array}{l}\text { transition of petroleum } \\
\text { enterprises, establish }\end{array}$ & & 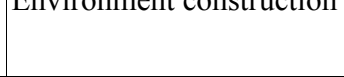 & $\begin{array}{l}\text { The deduction of greenhouse gas emissions caused by } \\
\text { new vegetation }\end{array}$ \\
\hline low carbon & & & The degree of office automation \\
\hline $\begin{array}{l}\text { development direction } \\
\text { of petroleum }\end{array}$ & Low carbon & $\begin{array}{l}\text { Enterprises internal } \\
\text { function management }\end{array}$ & $\begin{array}{l}\text { Human resources management of low carbon } \\
\text { transformation }\end{array}$ \\
\hline & management functions & & Financial management of low carbon transformation \\
\hline & & Enterprise external & Logistics management of low carbon transformation \\
\hline & & function management & Marketing management of low carbon transformation \\
\hline & & & The staff support rate of the low carbon economy \\
\hline & & $\begin{array}{l}\text { Policy support } \\
\text { enforcement }\end{array}$ & $\begin{array}{l}\text { Government, nonprofit organizations, the media, and } \\
\text { public opinion supervision of enterprises in low } \\
\text { carbon audit }\end{array}$ \\
\hline & 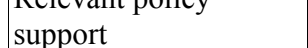 & & Sound level on low carbon tax, incentive mechanism \\
\hline & & Government & $\begin{array}{l}\text { Timeliness and persistence about enterprise } \\
\text { concerned about low carbon policy execution }\end{array}$ \\
\hline & & enforcement & $\begin{array}{l}\text { Clarity corporate taken on the agencies' } \\
\text { responsibilities energy saving emission and reduction }\end{array}$ \\
\hline
\end{tabular}




\section{Conclusions}

As for the traditional auditing of derivative, the low carbon audit asides that the traditional auditing reviews the traditional financial statements and frequent business of enterprises, and begins to look to the more far-reaching low carbon projects auditing. For the audit department, due to the lack of auditing standards and suitable auditing technology, what aspects of the contents of to audit, how to audit these problems are severe test, for enterprise, although the social from all walks of life has higher voice for the regulation of greenhouse gas emissions, but lack of effective monitoring means of disclosure, how to practice the real low carbon is a relatively vague concept. Therefore, based on the analysis of the connotation of low carbon audit, from the three phases of the low carbon - preparation, implementation, and end, it discusses the specific process of audit, at the same time based on researching, concluding, and summarizing a large number of low carbon economy and carbon emissions and other literature, through the investigation, and visiting to the experts, according to the existing literature and expert opinion, it tries to design a set of low carbon audit evaluation index system and provides guidelines for the smooth implementation of the low carbon audit of petroleum enterprises.

\section{References}

Iyer, E. K., \& Rao, B. (2014). A 360 degree carbon audit of the ICT industry. International Journal of Intercultural Information Management, 4, 158-182.

Lai, J. H. K., Yik, F. W. H., \& Man, C. S. (2012). Carbon audit: A literature review and an empirical study on a hotel. Facilities, 30, 9-10.

Li, H. F., \& Wang, X. F. (2010). Study on Chinese low carbon economic model. International Journal of Asian Business and Information Management, 4, 57-64.

Wang, L. (2010). Petroleum and chemical industry-Main force behind low-carbon economy. China Chemical Reporter, 13, $11-12$.

Xin, J. G., \& Wu, Y. X. (2011). The quantitative evaluation method of low-carbon economy auditing. Energy Procedia, 5, 1014-1018.

Zhang, W., \& Wu, Z. X. (2012). A study on establishing low-carbon auditing system in China. Low Carbon Economy, 3, 35-38.

Zhong, W. K. (2010). Petrochemical industry's role in low carbon economy. China Chemical Reporter, 21, 4-9. 